\title{
Urologic Surgery in Digital Era: Foresights and Futuristic Approach
}

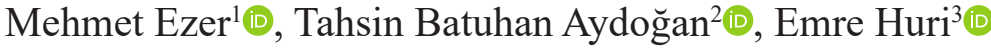

${ }^{1}$ Department of Urology, Kafkas University School of Medicine, Kars, Turkey

${ }^{2}$ Department of Urology, Ankara Liv Hospital, Ankara, Turkey

${ }^{3}$ Department of Urology, Hacettepe Univesity School of Medicine, Ankara, Turkey

The new scientific developments and technological opportunities that have led to significant changes all build up the digital era. In medicine, the use of new technologies in patient diagnosis and treatment processes has opened new horizons for physicians and patients. As considering for the medical training, 3-dimensional modeling opportunities, virtual reality, augmented reality, and various simulators offered by the new technologies of the digital era have become a new hope. The 3-dimensional scanning and modeling, 3-dimensional medical printing, virtual reality technologies applications and simulators in urology are very recent and valuable. Besides, the exoscope-assisted 3-dimensional open surgery provides high-resolution 3-dimensional images to surgeons with high comfort as compared with old-fashioned operating microscopes. New modalities that tried to be integrated in robotic surgery are 3-dimensional reconstruction, usage of indocyanine green, augmented reality, contrast ultrasound, haptic feedback, and availability of single port. Some new companies announced their new robotic systems in the market. The use of these new technological applications during medical training, especially at the beginning of the education curve for various surgical interventions, may be beneficial in terms of reducing possible complications that may be encountered due to inexperience at the beginning of the education process and increasing patient safety. Urology will also stay at the futuristic approach in medicine, while 3-dimensional technologies used more widely in this field.
New scientific developments and new technological opportunities in the 21 st century have led to significant changes in many areas of life. This period, in which we observe the breathtaking effects of computer technologies and the internet on our daily lives, is called the "Digital Era." One of the disciplines in which these developments have made the most important contributions is medicine. Today, patients can get an appointment for examination by pressing a single computer button, and physicians can access laboratory and imaging results in the same way. Beyond such conveniences, the use of new technologies in patient diagnosis and treatment processes has opened new horizons for physicians and patients.

The principle of "primum non nocere", that is, "first do no harm", of the Ionian physician Hippocrates, the founding father of medicine, is at the center of teachings of the art of medicine despite the centuries that have passed. The basis of traditional surgical teaching is William Stewart Halsted's "see one, do one, teach one" concept. However, the main problem in this concept is that the quality of the education that the person will receive is limited to the number of patient trainee who will be involved in the treatment. The risk of harming the human body, which is the main material of medical education, raises numerous ethical, moral, and legal problems. As a solution to these problems, cadavers and various animal models have been widely used until today. However, cadavers in terms of representing a living human body and important anatomical and physiological differences in animal models have important limitations in terms of education. Three-dimensional (3D) modeling opportunities, virtual reality (VR), augmented reality (AR), and various simulators offered by the new technologies of the digital era have become a new hope for overcoming these and similar difficulties in medical education.

In the historical days, when the "paternalistic" approach was more dominant in medicine, the physician decided many details with the treatment process of the patients. Today, patients actively participate in decisions about the treatment process. However, many patients are not capable of understanding the details of the treatment procedure to be applied and evaluating the pros and cons of

Corresponding author: Emre Huri, Department of Urology, Hacettepe Univesity School of Medicine, Ankara, Turkey

e-mail: emrehuri@hacettepe.edu.tr

Received: September 13, 2021 Accepted: September 28, 2021 Available Online Date: October 22, 2021 • DOI: 10.5152/balkanmedj.2021.21957

Available at www.balkanmedicaljournal.org

ORCID iDs of the authors: M.E. 0000-0003-4422-6768; T.B.A. 0000-0002-2000-7790; E.H. 0000-0001-5563-4527.

Cite this article as:

Ezer M, Batuhan Aydoğan T, Huri E. Urologic surgery in digital era: Foresights and futuristic approach. Balkan Med J.; 2021; 38(6):324-330.

Copyright@Author(s)-Available online at http://balkanmedicaljournal.org/ 
different treatment methods. The use of 3D medical technologies can enable patients to better understand the treatment process and to make more informed decisions in this process by providing visualization and concretization of the concepts that are tried to be explained to patients through abstract concepts. The solution of patient information was found in surgical planning.

An important area of use of 3D models, which are created by processing the patient's imaging examinations with computer-assisted design (CAD) programs, is preoperative surgical planning. In this way, the important neighborhood and anatomical location of tissues and organs can be evaluated in detail, and this information can be used to obtain the best surgical results.

The aim of this review is to give information about new technological developments that lead to many innovations and changes in the field of urological surgery and to talk about the reflections of these developments in the clinical field, creation of foresights, and futuristic approach.

\section{D Scanning and Modeling}

3D models of various tissues and anatomical formations can be obtained by processing images of cross-sectional imaging technologies such as computerized tomography (CT) and magnetic resonance imaging (MRI) obtained from patients with CAD software programs. Various training simulators can be created using technologies such as augmented reality, virtual reality, and mixed reality. The aim of the 3D models is to obtain more successful surgical results for the patients by making detailed planned studies before the surgical intervention on the materials printed using the 3D printers. Therefore, the first step towards the use of all these technologies is the scanning and modeling studies required to create $3 \mathrm{D}$ models. Creation of 3D models using real patient data is the key step for the production of virtual or physical patient-specific simulators.

Cross-sectional images such as CT and MRI of the patient are called as a standard format DICOM (digital imaging and communications in medicine). ${ }^{1}$ The data arranged in DICOM format are first segmented by means of CAD programs. In order to obtain a more realistic $3 \mathrm{D}$ model, editing and repair operations are performed on the program in order to remove the artifacts that occur due to the resolution and quality of the imaging technique. ${ }^{2}$ After these processes, a realistic 3D model is obtained in the file format called "The Standard Tesselation Language" or "Standard Triangle Language", and its abbreviation is expressed as ".stl". Many small triangles in ".stl" format come together with different angles to give information about the anatomical surface structure of the 3D model (Figure 1). It has been possible to express different features in different formats developed after the ".stl" format. While color and pattern features can be expressed in addition to anatomical features in the ".obj" format (Figure 2), transparency can also be expressed in the ".ply" format. ${ }^{3}$

After all these stages, the realistic anatomic 3D model obtained from the patient's images can be used in augmented reality, virtual reality applications, or can be printed with $3 \mathrm{D}$ printers.

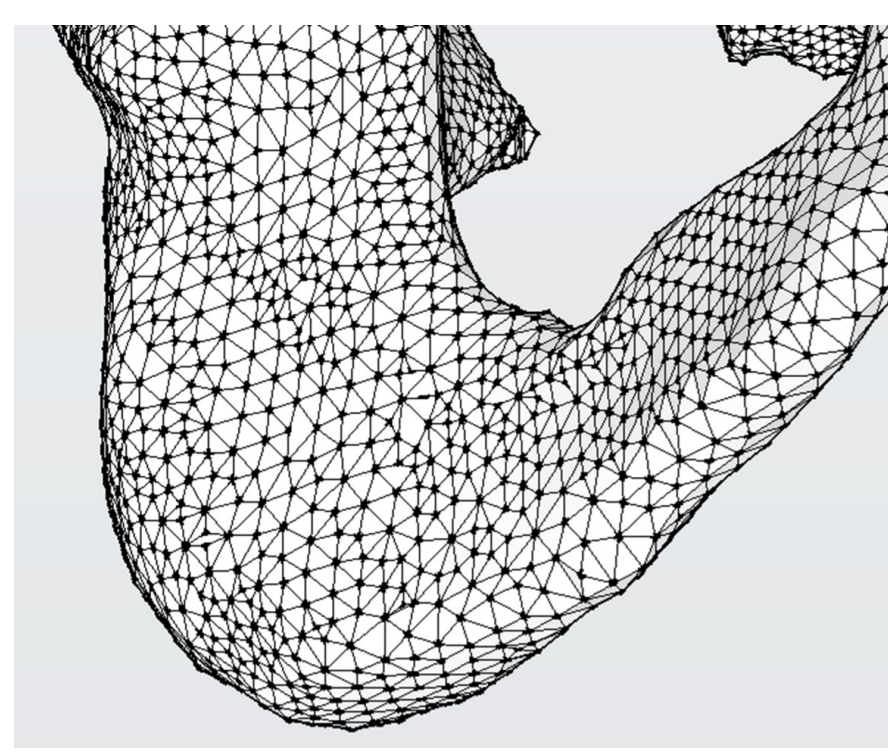

FIG. 1. From the bone pelvis study modeled in 3D using the ".stl" format, triangles can be selected in the detailed image of the area where the right ischial and pubis bones meet (from Dr. Ezer's 3D modeling archive).

\section{D Medical Printing}

$3 \mathrm{D}$ printers are machines that convert $3 \mathrm{D}$ designs created in $\mathrm{CAD}$ systems into genuine $3 \mathrm{D}$ things made of diverse materials. The era of 3D printers began in 1986 with the polymerization of an

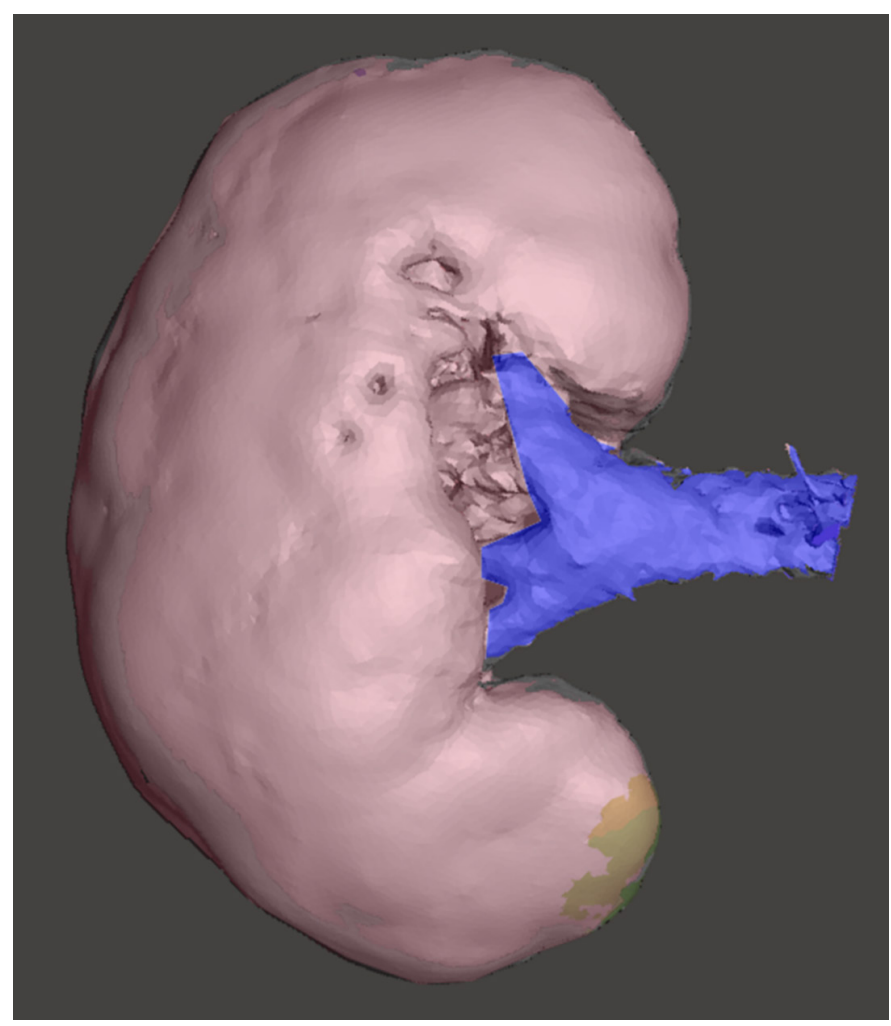

FIG. 2. A right kidney modeled in ".obj” format (from Dr. Ezer's 3D modeling archive). 


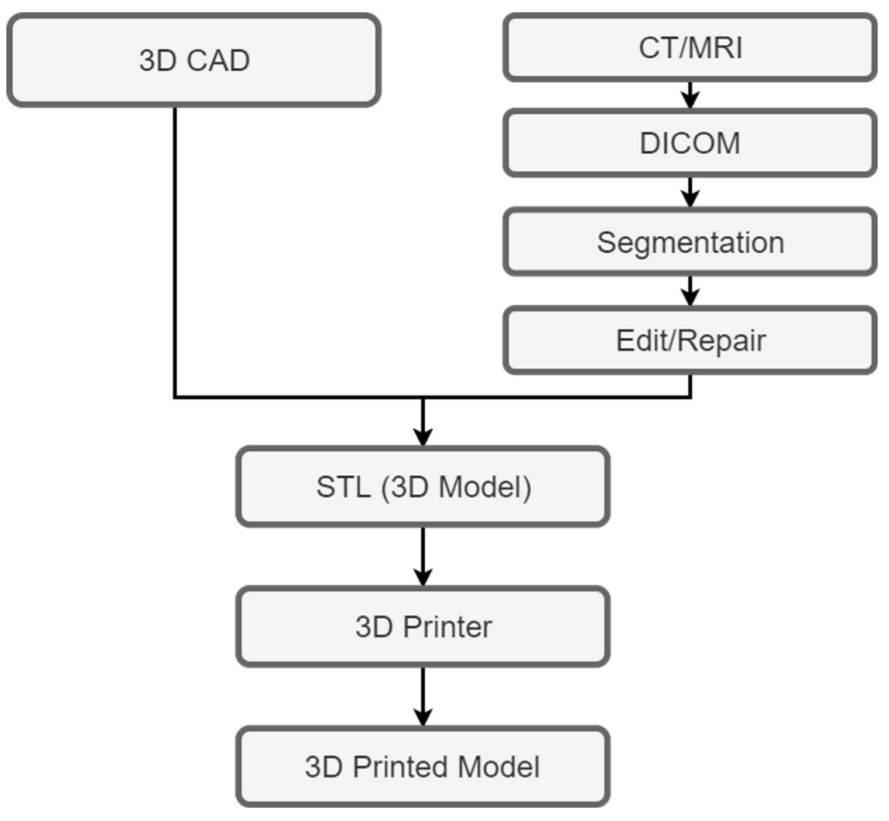

FIG. 3. 3D Printing process from design to product. CAD, Computer-Assisted Design programs; CT/MRI, Computerized Tomogtaphy/Magnetic Resonance Imaging; STL, Standart Triangle Language.

ultraviolet (UV) light-sensitive resin by Charles W. Hull. ${ }^{4}$ D printers were first used in industries such as aerospace, automotive, and architecture, and with the transformation, they have undergone over time and have now evolved into household devices where individuals can create their own special designs. There are many different 3D printer technologies such as fused deposition modeling (FDM), inkjet printing (material jetting), powder-based printing, laser recine-based printing (SLE), and vat polymerization-based printing, each of which gives the opportunity to print using different materials for different purposes. ${ }^{5}$ Today, many different materials can be used in 3D printers, from various polymers to ceramics, from metals to wax, and even human cells. ${ }^{6-8} 3 \mathrm{D}$ printing technology is also called additive manufacturing (AM) or subtractive manufacturing (SM).

Although the history of 3D printers goes back to the 1980 s, they have been used in the field of medicine for the last few decades. ${ }^{9}$ $3 \mathrm{D}$ printers are mostly used in the field of urology in preoperative and intraoperative planning, patient information, training of residents and students, and production of surgical materials.

It is difficult to detect the placement and neighborhood of tissues and organs in 3D space with 2-dimensional (2D) conventional cross-sectional imaging methods. 3D models obtained with CAD programs from conventional radiological images of the patient can provide more accurate surgical planning by providing better anatomical information during preoperative planning. Partial nephrectomy, also called "nephron-sparing surgery", is the gold standard treatment for small renal masses. During the partial nephrectomy, details such as the depth of the mass, whether there is an invasion into the collecting system and the distance to the renal pedicle, affect the surgical plan. In the study published by Smektala et $\mathrm{al}^{10}$ in 2017, preoperative 3D models of patients who were planned to undergo laparoscopic partial nephrectomy were prepared. After the surgical team first worked on these models, partial nephrectomy was performed on the patients. The authors suggested that performing the actual surgery after preparation on these models had a positive effect on the ischemia time. Westerman et al, ${ }^{11}$ in their study, in which they compared the use of models created using CAD programs and printed on 3D printers with the use of models created only in the virtual computer environment in difficult partial nephrectomy cases, suggested that plans using models printed by 3D printers were more successful. ${ }^{11}$ Today, it is well known that $3 \mathrm{D}$ modeling units are located in hospitals to obtain 3D surgical planning for complex cases in which decreased operation time and less hospitalization period are needed.

One of the most important limiting factors in surgical training is the possibility of harming the human body during training. For this reason, alternatives to the human body have been searched, which is the main target of education. Cadavers, animal models, and bench models have been used for educational purposes until today. The use of 3D models in education, obtained by processing real images of the patient, promises important contributions to the field of education. One of the cornerstones of a successful surgical procedure is a good knowledge of anatomy. Understanding the adjacent organs and relations of anatomical structures with each other requires a good 3-D understanding. 2-dimensional images obtained with conventional imaging methods can make it difficult for inexperienced clinicians to understand important anatomical relationships. A study was conducted to evaluate the residents' understanding of anatomical relationships of different images of anatomical structures using standard 2D images and 3D models. ${ }^{12}$ It has been shown that junior residents perform anatomical evaluation more successfully with $3 \mathrm{D}$ models. There was no significant difference between $3 \mathrm{D}$ and $2 \mathrm{D}$ images in senior residents. This indicates that the use of 3D models in the early stages of residency will contribute to anatomical understanding. In a study by Atalay et al, ${ }^{13}$ 3D kidney models of 5 different patients, which were created with the help of CAD programs before PNL surgery, were printed on a 3D printer, and replicas were created. PNL training was given to urology residents using these models. Residents trained on these models improved their ability to understand the location of the stone in the anterior or posterior calyx and to decide on the percutaneous access point by $60-88 \%$.

Nowadays, patients can easily access information about their health problems. A patient who is well-informed about the current health problem can be more effectively involved in the decisions to be made about the treatment process. In patients whose treatment process requires surgical intervention, explaining the organs and tissues to the patient by visualizing them with a 3D model will significantly contribute to the patient's better understanding of the process. In a study by Atalay et al, ${ }^{14}$ the $3 \mathrm{D}$ kidney model of the patient, which was created with the help of CAD programs before the PNL surgery, was printed on a 3D printer and used to inform the patients before the surgery. Researchers had made patients' fill out 


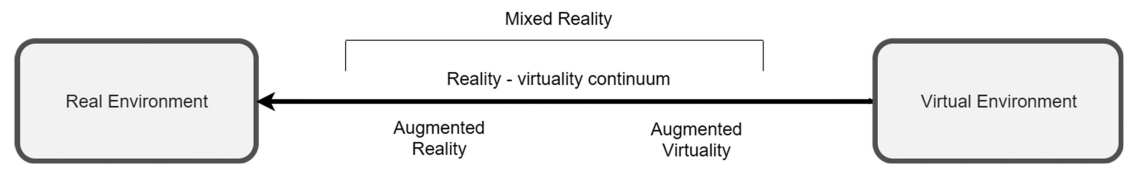

FIG. 4. Reality continuum diagram.

an evaluation questionnaire before and after this briefing. After the briefing using the 3D model, they observed a significant increase in knowledge from kidney anatomy to stone location and complications of the procedure.

Another area where 3D printers are used in urology is the production of some surgical materials. In 2015, a study was published in which pressure measurements were made on a double J stent (DJS) model produced with a 3D printer, which exhibits anti-reflux features, thanks to the polymeric valves. ${ }^{15}$ In another study by del Junco and colleagues, the flow characteristics of DJSs produced with a 3D printer and standard stents were compared in the pig model. ${ }^{16}$ There are also publications in the literature showing that laparoscopic surgical instruments such as trocars are produced with 3D printers. ${ }^{17}$

\section{Reality Technologies Applications and Simulators in Urology}

Although there are many definitions in the literature about reality technologies, the most accepted definition is the one made by Milgram and Kishino. ${ }^{18}$ According to the authors, the transition between reality, augmented reality, and virtual reality is continuous (Figure 4).

Virtual reality is defined as a computer interface that presents an interactive and real-time world to the user with 3-D simulations, created by a computer using multi-sensor methods. The virtual reality user is isolated from the real environment and feels to be in an artificial environment. Augmented reality, a variation of virtual reality, is a concept introduced to the scientific world by Thomas Caudell, ${ }^{19}$ who worked on Boeing airplanes in the early 90s. In augmented reality technology, multimedia elements such as digitally produced images, audio, and video on the computer are added to the real-world environment. Unlike virtual reality applications, in augmented reality, the person is aware of the real environment. In augmented reality, the real-world environment is presented to the user as enriched and modified with computer-assisted additions. Mixed reality technology combines virtual and physical environments into a new real environment, using both virtual reality and augmented reality technologies. The most important feature that distinguishes this new technology in augmented reality technology is that the created virtual objects and data can be interacted with and used by users in real time.

In a study in which virtual reality applications were used for preoperative surgical planning and patient education, one group of surgeons examined only the conventional radiological images of the patient, while another group of surgeons worked on the patient-specific anatomy in a virtual reality environment created with oculus rift displays (VR headsets) mounted on their heads. ${ }^{20}$ In the evaluations made between the two groups, surgeons who evaluated the patient with virtual reality method compared to surgeons who only looked at conventional images, it was determined that the duration of fluoroscopy use and the amount of bleeding were lower, stone-free rates were higher, and the number of renal accesses was fewer.

With augmented reality technology, the images obtained from the CT and MRI images of the patient taken before the operation can be superimposed directly on the patient during open surgery or with the images obtained during laparoscopy or robotic surgery. In this way, the patient's data obtained by imaging methods

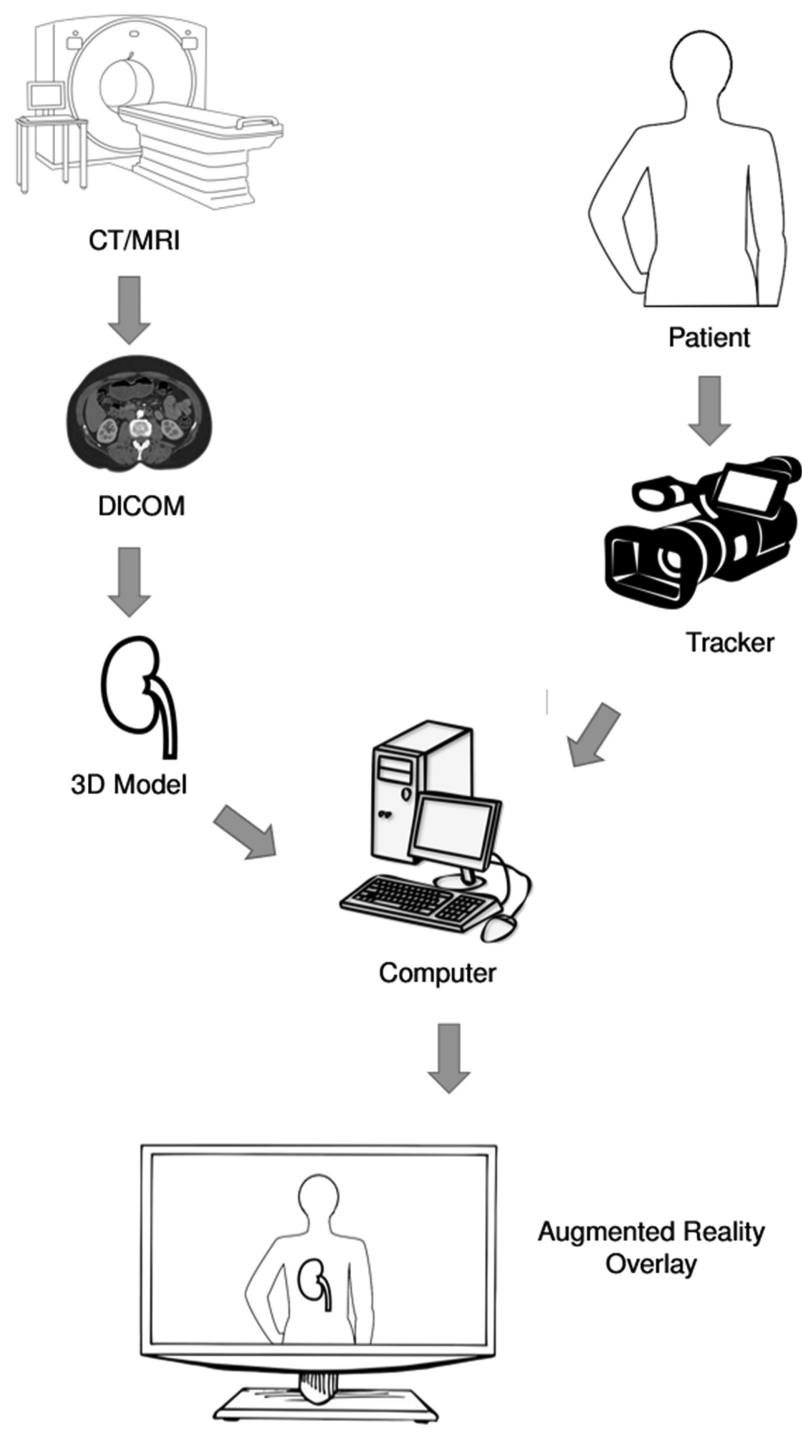

FIG. 5. In augmented reality technology, the models obtained from the patient's MR and CT images are superimposed on the real image of the patient on the monitor, tablet, or goggles screen. 
and real images can be seen at the same time, and the relations of anatomical structures with each other can be better evaluated (Figure 5).

Most of the procedures applied in the field of urological surgery are performed endoscopically, laparoscopically, and robotically. The common point of these methods is that the whole surgical team, including the primary surgeon who performed the procedure, follows the operation on the screen. Simulating these procedures using reality applications are easier than simulating open surgical methods. Even if the training effectiveness of simulators is limited for an experienced surgeon, a well-planned, step-by-step simulation system can be very useful for less-experienced residents. Detailed training on the simulator will not only shorten the operation time but also reduce the possibility of complications. ${ }^{21}$

Endoscopic procedures performed on the lower urinary tract constitute an important part of urological surgery practice. Ballaro et $\mathrm{a}^{22}$ reported a TUR-P simulator operating in a virtual reality environment in 1999. In a study published by Schout et $\mathrm{al}^{23}$ in 2009, the simulator named "UroTrainer" produced by Karl Storz for the simulation of transurethral resection procedures was evaluated. ${ }^{23}$ Although these simulators do not provide realistic surgical experience, they allow beginners to familiarize themselves with this procedure before trying it on a patient. With the development of technology, the development of more realistic simulators will lead to revolutionary developments in this field.

\section{Exoscope-Assisted 3D Open Surgery}

After the use of binocular microscopes in surgery in the 20th century, operating microscopes $(\mathrm{OM})$ began to be preferred by urologists in andrology and pediatric cases. ${ }^{24}$ The current definition of focal length for OM providing magnification from $\times 4$ to $\times 40$ is an adjustable distance of $200-400 \mathrm{~mm}$ from the operating field to the farthest part of the lens. This distance allows the use of tools without distorting the image. The split view from monocular lenses to binocular lenses provides a 3D view called stereopsis. ${ }^{25}$ Overall, the disadvantages of OM are that it is expensive, large, and difficult to relocate. It can also cause fatigue and neck pain in surgeons.

Introduced in 2008, the video telescope operating monitor (VITOM) is a powerful alternative for both OM and endoscope systems. In addition to magnification, VITOM provides a large surgical field. The initial VITOM models were enabling a 2-D (two-dimensional) view. The surgeon has needed a well developed stereopsis and tactile sensativity for hand-eye coordination during surgery. Nowadays with aid of technology 3-D (threedimensional) exoscopes are in use which enables a high quality view. ${ }^{25}$ The high-resolution exoscope system basically consists of 4 units; operation telescope, camera head, light source, and highdefinition video monitor. The difference from OM is that the camera and telescope can be resterilized and do not require the use of sterile covers. The telescope holder is easier to use because it is compact and smaller in size. In addition, the exoscope system $(650 \mathrm{~g})$ is lighter than the OM (>100 kg).
Mamelak et $\mathrm{a}^{26}$ performed the first surgical experience during craniotomies and brain dissections in pig models and published it as an article in 2010. When OM and VITOM were compared, surgeons felt the lack of stereopsis, but stated that this could be eliminated with repeated experience. Optical quality has been evaluated as successful by surgeons. In 2013, 3 surgeons from pediatric surgery and urology prepared a preliminary report evaluating the use of VITOM instead of the surgical loop when augmentation is required in complex surgeries. ${ }^{27}$ Since 2017, the first VITOM 3D model experiences have started to take place in the literature. ${ }^{28,29} \mathrm{In}$ all these studies, it was emphasized that the image quality was good, the residents and technicians understood the procedures well, and the surgeries were more comfortable. Lack of stereopsis was reported as the most striking negative. It was also noted that repositioning is not as easy as in OM.

Higher resolution 3D images are needed for most surgical approaches. VITOM systems are one of the new technologies developed for this purpose. Thanks to these developments that increased the comfort of the surgeon, the quality of assistant training, and the success of the surgery. However, further development is still needed for repositioning the exoscope holders.

\section{The Future of Robotic Systems in Urology}

In the near future, robotic surgery is expected to be easily accessible at affordable prices, even in outpatient surgery centers. At the point where technology has come, it is expected that different and new modalities such as virtual reality and 3D modeling will often be integrated into robotic surgery.

The first robot used for surgical purposes is Arthrobot, which was used to assist orthopedic surgical procedures in Canada in 1983. Entering the 21st century, the name "da Vinci" (Intuitive Surgical, Inc., Sunnyvale, Calif, USA) was first encountered in the robot-assisted heart surgery performed in Leipzig, Germany ${ }^{30}$ The main capabilities of the da Vinci robotic system are 3-D vision, intuitive motion, and endo-wrist instrumentation. ${ }^{31}$ In the following years, important and revolutionary features were added such as fourth arm, high-resolution image quality, dual-console, and 3D-HD camera that fits all ports. ${ }^{32}$ With the addition of GelPOINT (Applied medical resources, Rancho Santa Margarita, CA) to the da Vinci system, strides have been made in protecting patients from the pressure of robotic arms and in more comfortable relocation of trocars. $^{33}$

The first robot-assisted radical prostatectomy (RARP) was published by Abbou et al in 2000, the first robot-assisted radical cystectomy was published by Menon et $\mathrm{al}^{34}$ in 2003 , and the robot-assisted partial nephrectomy (RAPN) was published by Gettman et $\mathrm{al}^{35}$ in 2004. ${ }^{33-35}$ Such robot-assisted operations have known advantages such as shorter hospital stay, faster recovery, less bleeding, and less pain. As robotic surgery became widespread around the world and that the surgical experience has increased, additional surgeries such as nephroureterectomy, adrenal surgery, robotic prostate adenomectomy, bladder diverticulectomy, and ureteral reimplantation 
began to be performed. With the widespread use of multiparametric $\mathrm{MR}$ in prostate imaging, robotic partial prostatectomy has also come to the fore. ${ }^{36}$ Lotan et $\mathrm{al}^{37}$ suggested that 10 cases per week or 250 cases per year may be necessary for the use of robots in surgery to be cost-effective. The difficulties to overcome in robotic surgery are: occupying a lot of room in the operating room, long preparation time, long training time, and low return on investment. Some of the new companies announcing their new robotic systems in the market are Medtronic, Senhance, Avatera, Versius, Titan Medical, and Elmed Medical (Ankara, Turkey). Robotic systems produced by all these brands have pros and cons in terms of cost, size, ergonomics, comfort, arm size, and haptic feedback. Thanks to haptic feedback, it is possible for the surgeon to feel the current tension and to reduce possible injuries. There is a view that single-incision SP robotic systems will be the standard of the future in the world. It has advantages such as faster recovery and less operative pain and disadvantages such as poor ergonomics and loss of triangulation.

New modalities that tried to be integrated into robotic surgery are 3D reconstruction, indocyanine green (ICG), augmented reality, and contrast ultrasound. ${ }^{36}$ Virtual reality applications in robotic surgery training are frequently preferred, because they increase surgical ability, decrease the operation time, and reduce intraoperative errors. ${ }^{38}$ However, mixed reality applications, which combine the real and virtual worlds, are considered as a more suitable option, as VR may cause dizziness as a side effect. With the advancement of technology and the increase in internet speed, it is on the agenda to take further steps in remote-controlled robotic surgery. In international and intercontinental online live connections, surgeries can be performed by separated robotic arms and consoles by robot mentors far from each other. Due to these rapid developments, it is expected that open surgical procedures will decrease over the years. Newly developed robotic systems will provide us with new surgical approaches and comfort in intraoperative navigation. More recent comparative scientific studies are needed to better evaluate robotic systems.

In addition to the contributions of new technological developments to our daily life, the innovations brought in the field of medicine have led to really impressive changes. Thanks to the use of virtual reality technologies, the chance to try countless possibilities without making any changes in the real world and offering a good preoperative planning and training opportunity. When the current technology is evaluated, it is an indisputable fact that 3D printers, augmented, and virtual reality technologies cannot replace clinical training given on a real case. However, the use of these new technological applications in the education of less experienced residents, especially at the beginning of the education curve, may be beneficial in terms of reducing possible complications that may be encountered due to inexperience at the beginning of the education process and increasing patient safety. 3D technologies are among the most important tools of physicians in informing patients and their relatives about the disease and treatment processes. It is thought that in the future, 3D technologies will be used more widely in the field of medicine with the decrease in costs as a standard of care. Urology will also stay at the futuristic approach in medicine for years.
Author Contributions: Concept - E.H.; Design - E.H.; Supervision - E.H.; Materials M.E.; Data Collection and/or Processing - M.E.; Analysis and/or Interpretation - M.E., T.B.A.; Literature Review - M.E., T.B.A.; Writing - M.E., T.B.A.; Critical Review E.H.

Conflict of Interest: The authors have no conflicts of interest to declare.

Funding: The authors declared that this study had received no financial support.

\section{REFERENCES}

1. Prior FW. Specifying DICOM compliance for modality interfaces. Radiographics. 1993;13(6):1381-1388. [CrossRef]

2. Tatar İ, Huri E, Selçuk İ, Moon YL, Paoluzzi A, Skolarikos A. Review of the effect of 3D medical printing and virtual reality on urology training with 'MedTRain3DModsim' Erasmus + European Union Project. Turk J Med Sci. 2019;49(5):1257-1270. [CrossRef]

3. Parikh N, Sharma P. Three-dimensional printing in urology: history, current applications, and future directions. Urology. 2018;121:3-10. [CrossRef]

4. Hull CW. Apparatus for production of three-dimensional objects by stereolithography. Google Patents; 1986.

5. Chen MY, Skewes J, Desselle M, et al. Current applications of three-dimensional printing in urology. BJU Int. 2020;125(1):17-27. [CrossRef]

6. Schubert C, Van Langeveld MC, Donoso LA. Innovations in 3D printing: a 3D overview from optics to organs. Br J Ophthalmol. 2014;98(2):159-161. [CrossRef]

7. Seol YJ, Kang HW, Lee SJ, Atala A, Yoo JJ. Bioprinting technology and its applications. Eur J Cardiothorac Surg. 2014;46(3):342-348. [CrossRef]

8. Murphy SV, Atala A. 3D bioprinting of tissues and organs. Nat Biotechnol. 2014;32(8):773-785. [CrossRef]

9. Cacciamani GE, Okhunov Z, Meneses AD, et al. Impact of three-dimensional printing in urology: state of the art and future perspectives. A systematic review by ESUTYAUWP group. Eur Urol. 2019;76(2):209-221. [CrossRef]

10. Golab A, Smektala T, Kaczmarek K, Stamirowski R, Hrab M, Slojewski M. Laparoscopic partial nephrectomy supported by training involving personalized silicone replica poured in three-dimensional printed casting mold. J Laparoendosc Adv Surg Tech A. 2017;27(4):420-422. [CrossRef]

11. Westerman ME, Matsumoto JM, Morris JM, Leibovich BC. Three-dimensional printing for renal cancer and surgical planning. Eur Urol Focus. 2016;2(6):574-576. [CrossRef]

12. Lin $\mathrm{C}$, Gao J, Zheng $\mathrm{H}$, et al. When to introduce three-dimensional visualization technology into surgical residency: a randomized controlled trial. J Med Syst. 2019;43(3):71. [CrossRef]

13. Atalay HA, Ülker V, Alkan İ, Canat HL, Özkuvancı Ü, Altunrende F. Impact of threedimensional printed pelvicaliceal system models on residents' understanding of pelvicaliceal system anatomy before percutaneous nephrolithotripsy surgery: a pilot study. J Endourol. 2016;30(10):1132-1137. [CrossRef]

14. Atalay HA, Canat HL, Ülker V, Alkan İ, Özkuvanci Ü, Altunrende F. Impact of personalized three-dimensional-3D-printed pelvicalyceal system models on patient information in percutaneous nephrolithotripsy surgery: a pilot study. Int Braz J Urol. 2017;43(3):470-475. [CrossRef]

15. Park CJ, Kim HW, Jeong S, et al. Anti-reflux ureteral stent with polymeric flap valve using three-dimensional printing: an in vitro study. J Endourol. 2015;29(8):933-938. [CrossRef]

16. Del Junco M, Yoon R, Okhunov Z, et al. Comparison of flow characteristics of novel three-dimensional printed ureteral stents versus standard ureteral stents in a porcine model. J Endourol. 2015;29(9):1065-1069. [CrossRef]

17. del Junco M, Okhunov Z, Yoon R, et al. Development and initial porcine and cadaver experience with three-dimensional printing of endoscopic and laparoscopic equipment. J Endourol. 2015;29(1):58-62. [CrossRef]

18. Milgram P, Colquhoun H. A taxonomy of real and virtual world display integration. Mixed Reality: Merging Real Virtual Worlds. 1999;1999(1):1-26.

19. Caudell T, Mizell D. Augmented reality: an application of heads-up display technology to manual manufacturing processes. Proceedings of the Twenty-Fifth Hawaii International Conference on System Sciences. 1992;2(1):659-669. [CrossRef]

20. Parkhomenko E, O'Leary M, Safiullah S, et al. Pilot assessment of immersive virtual reality renal models as an educational and preoperative planning tool for percutaneous nephrolithotomy. J Endourol. 2019;33(4):283-288. [CrossRef] 
21. Aggarwal G, Adhikary SD. Simulators in the urological training armamentarium: a boon or a bane? Arab J Urol. 2017;15(2):166-169. [CrossRef]

22. Ballaro A, Briggs T, Garcia-Montes F, MacDonald D, Emberton M, Mundy AR. A computer generated interactive transurethral prostatic resection simulator. $J$ Urol. 1999;162(5):1633-1635. [CrossRef]

23. Schout BM, Bemelmans BL, Martens EJ, Scherpbier AJ, Hendrikx AJ. How useful and realistic is the uro trainer for training transurethral prostate and bladder tumor resection procedures? J Urol. 2009;181(3):1297-1303; discussion 303. [CrossRef]

24. Schultheiss D, Denil J. History of the microscope and development of microsurgery: a revolution for reproductive tract surgery. Andrologia. 2002;34(4):234-241. [CrossRef]

25. Mamelak AN, Danielpour M, Black KL, Hagike M, Berci G. A high-definition exoscope system for neurosurgery and other microsurgical disciplines: preliminary report. Surg Innov. 2008;15(1):38-46. [CrossRef]

26. Mamelak AN, Nobuto T, Berci G. Initial clinical experience with a high-definition exoscope system for microneurosurgery. Neurosurgery. 2010;67(2):476-483. [CrossRef]

27. Frykman PK, Duel BP, Gangi A, Williams JA, Berci G, Freedman AL. Evaluation of a video telescopic operating microscope (VITOM) for pediatric surgery and urology: a preliminary report. J Laparoendosc Adv Surg Tech A. 2013;23(7):639-643. [CrossRef]

28. Rossini Z, Cardia A, Milani D, Lasio GB, Fornari M, D’Angelo V. VITOM 3D preliminary experience in cranial surgery. World Neurosurg. 2017;107:663-668. [CrossRef]

29. Oertel JM, Burkhardt BW. Vitom-3D for exoscopic neurosurgery: initial experience in cranial and spinal procedures. World Neurosurg. 2017;105:153-162. [CrossRef]
30. Autschbach R, Onnasch JF, Falk V, et al. The Leipzig experience with robotic valve surgery. J Card Surg. 2000;15(1):82-87. [CrossRef]

31. Yates DR, Vaessen C, Roupret M. From Leonardo to da Vinci: the history of robotassisted surgery in urology. BJU Int. 2011;108(11):1708-1713; discussion 14. [CrossRef]

32. Rassweiler JJ, Autorino R, Klein J, et al. Future of robotic surgery in urology. BJU Int. 2017;120(6):822-841. [CrossRef]

33. Dobbs RW, Halgrimson WR, Talamini S, Vigneswaran HT, Wilson JO, Crivellaro S Single-port robotic surgery: the next generation of minimally invasive urology. World J Urol. 2020;38(4):897-905. [CrossRef]

34. Menon M, Hemal AK, Tewari A, et al. Nerve-sparing robot-assisted radical cystoprostatectomy and urinary diversion. BJU Int. 2003;92(3):232-236. [CrossRef]

35. Gettman MT, Blute ML, Chow GK, Neururer R, Bartsch G, Peschel R. Roboticassisted laparoscopic partial nephrectomy: technique and initial clinical experience with DaVinci robotic system. Urology. 2004;64(5):914-918. [CrossRef]

36. Falagario U, Veccia A, Weprin S, et al. Robotic-assisted surgery for the treatment of urologic cancers: recent advances. Expert Rev Med Devices. 2020;17(6):579-590. [CrossRef]

37. Lotan Y, Cadeddu JA, Gettman MT. The new economics of radical prostatectomy: cost comparison of open, laparoscopic and robot assisted techniques. $J$ Urol. 2004;172(4 Pt 1):1431-1435. [CrossRef]

38. Checcucci E, De Cillis S, Porpiglia F. 3D-printed models and virtual reality as new tools for image-guided robot-assisted nephron-sparing surgery: a systematic review of the newest evidences. Curr Opin Urol. 2020;30(1):55-64. [CrossRef] 